\title{
Prevalence and Antibiotic sensitivity pattern of Salmonella isolates from milk products and water reservoirs in Maiduguri, North-Eastern Nigeria
}

\author{
Jasini Athanda Musa ${ }^{1 *}$, Kwoji Iliya Dauda ${ }^{1}$, Fati Adamu Lawan ${ }^{1}$, Dauda Diyo ${ }^{2}$, \\ Maina Maunta Meshack ${ }^{1}$ Solomon Jauro ${ }^{1}$ \\ ${ }^{I}$ Department of Veterinary Microbiology, University of Maiduguri, Nigeria \\ ${ }^{2}$ Faculty of Veterinary Medicine University of Maiduguri, Nigeria
}

\begin{abstract}
The study was conducted to determine the presence of Salmonella in retail milk products and water reservoirs in Maiduguri, Nigeria. A total of 150 samples were collected using convenient sampling technique. One hundred samples; fifty each of full cream milk or Kindirmo ( $n=50)$ and Skimmed milk or Nono $(n=50)$ were collected from Bulumkutu and Monday market retail sellers. Furthermore, of the fifty samples obtained from the two different locations, twenty five samples each of kindirmo and nono were collected. The samples were aseptically kept in sterile plastic bags. Additionally, fifty water samples were collected from reservoirs within the University campus. They were processed according to standard bacteriological protocols followed by Gram's staining and biochemical test; Triple sugar iron test, citrate and urease. The Salmonella isolates were further subjected to ten different antibiotics to determine their sensitivity. The overall prevalence of Salmonella in milk samples was found to be $10.00 \%$, while the total prevalence of Salmonella from water sample was 40.00\%. Of the fifteen isolates tested, resistance to Amoxicillin, Ceftriaxone and Erythromycin was $100.00 \%$, Gentamicin had $80.00 \%$ and Cotrimoxazole was $53.33 \%$, whereas Gentamycin, Ceftriaxone and Amoxicillin displayed $100.00 \%$ sensitivity. Moderate sensitivity of 53.33\% to Streptomycin and Pefloxacin, $46.67 \%$ to Ciprofloxacin and $86.67 \%$ sensitivity to Ofloxacin was found in this study. Antibiotic resistance is associated with frequent usage both in livestock and humans as they are commonly available. Adequate sanitary measures should be ensured in milk processing and use of water reservoirs. Antibiotics should be used based on their antibiogram pattern. Prudent use of antibiotics is essential and its continuous use as growth promoters should be discouraged, as this may result to failure in the treatment of Salmonella-associated diseases due to resistance. Disease surveillance programmes should be established as a means for curtailing salmonellosis.
\end{abstract}

Keywords: Salmonella, prevalence, milk, water reservoir, antibiotics, susceptibility, Nigeria

\section{Introduction}

Salmonella are widely distributed in nature and survive well in a variety of foods and contamination can occur at multiple steps along the food chain (Pui et al., 2011). The non-typhoidal Salmonella serovars are predominantly associated with food of animal origin such as milk, eggs, poultry, beef and pork (Kaushik et al., 2014). The infection dose of Salmonella can be as low as 15 to 20 cells, depending on the age and health of the susceptible host (Zaki et al., 2009). It causes inflammation of the gastrointestinal tract and in some cases, if the immune response is not sufficiently powerful and treatment is not instituted, can become systemic and cause more serious conditions throughout the body. The bacteria cause infection by invading the epithelial cells of the small intestine and macrophages. Infants, elderly and immunocompromised individuals are at high risk of the disease (Ricci-Tam, 2008). Salmonella has more than 2,500 different serovars and are considered pathogenic to humans (Kemal, 2014).

Salmonellosis is an infection of the digestive system caused by Salmonella serotypes and characterized clinically by one or more of the three major syndromes; septicaemic, acute and chronic enteritis, which infect both humans and animals with millions of illness, reported worldwide (Kemal, 2014). Food borne salmonellosis constitutes a major health problem in many countries (Bayu et al., 2013).

Salmonellosis is transmitted by ingestion of contaminated food, water or contact with environment infected with Salmonella organisms. Symptoms usually develop between 6-72 hours post-infection, which includes watery diarrhea, fever, headache, abdominal pain, nausea, vomiting and loss of appetite (WHO, 2013). Intestinal salmonellosis typically resolves in five to seven days and does not require treatment with antibiotics. When infection spreads beyond the intestinal tract, appropriate antimicrobial therapy, such as Ciprofloxacin and Ceftriaxone in adult and children may be lifesaving (White et al., 2001). The prevention and control of microbial diseases such as salmonellosis with prior isolation, identification and characterization of that particular etiological agent may be needful (Mondal et al., 2008). It is best prevented by good hygiene, avoiding 
unpasteurized milk or products made from it (CFSPH, 2006). Drinking of clean, filtered and boiled water is recommended to avoid infection with Salmonella species.

Salmonella is one of the most common causes of food borne diarrheal disease worldwide, a zoonosis which can be transmitted through contaminated food such as milk (Wegener et al., 2003). Most herdsmen and some dairy farms do not disinfect the teats and udders prior to milking and there could be the possibility of contamination at critical control points in the course of processing. Salmonellosis remained a significant cause of economic loss in farm animals, due to expenses which are incurred from clinical disease including treatment of clinical cases, cleaning and disinfection and cost of prevention and control (Kemal, 2014). Therefore, heavy economic losses occur due to morbidity, mortality and reduce production (Mondal et al., 2008). Great microbial risks are associated with ingestion of water contaminated with human or animal faeces (Cabral, 2010). Polluted or contaminated sources of drinking water carry a number of pathogens that causes diarrhoea and typhoid fever (Nagpal et al., 2011). Water borne infection is prevalent where general hygiene and environmental sanitation are poor and where there is shortage of protected water supply (Demena et al., 2003).

The research was aimed to identify and provide information on Salmonella in milk products sold at retail outlets and water from reservoirs in Maiduguri, which may be pathogenic to animals and humans.

\subsection{Study Area}

\section{Materials And Methods}

This study was conducted in Maiduguri metropolis, Borno State located in North-Eastern Nigeria.

\subsection{Study Design and Sample Collection}

The study design was a cross sectional study. A total of 150 samples were collected using convenient sampling technique (Portney and Watkins, 2007). Of the one hundred samples; fifty each of full cream milk or Kindirmo $(n=50)$ and Skimmed milk or Nono $(n=50)$ were aseptically sampled from Bulumkutu and Monday market retail sellers. Furthermore, of the fifty samples obtained from the two different locations, twenty five samples each of kindirmo and nono were collected. The samples were aseptically kept in sterile plastic bags. Additionally, fifty water samples $(n=50)$ from fifty different water reservoirs were collected in sterile sample bottles from a University campus. All the samples were labelled properly and immediately transported on ice packs in a Coleman ${ }^{\circledR}$ box to the Veterinary Microbiology laboratory, Faculty of Veterinary Medicine, University of Maiduguri where they were immediately processed.

\subsection{Sample Processing}

\subsubsection{Processing of milk samples}

One milliliter $(1 \mathrm{ml})$ of each of the fifty samples of kindirmo $(n=25)$ and nono $(n=25)$ from Bulumkutu retail market were inoculated into $10 \mathrm{ml}$ of Selenite $\mathrm{F}$ broth and incubated at $37^{\circ} \mathrm{C}$ for 24 hours. Similarly, samples from Monday market comprising of full cream milk (kindirmo $=25$ ) and skimmed milk $($ nono $=25$ ) were inoculated into Rappaport Vassiliadis broth (Oxoid-CMO669) and then incubated at $37^{\circ} \mathrm{C}$ for 24 hours. Loopful of the broth cultures were subcultured onto Xylose lysine desoxycholate (XLD) (ISO, 2002) and incubated for $24-48$ hours at $37^{\circ} \mathrm{C}$ to observe for the typical growth indicative of Salmonella.

All samples that exhibited characteristic colonies of Salmonella were subcultured onto Nutrient agar slants and then stored at $4^{\circ} \mathrm{C}$ until required.

\subsubsection{Gram Staining}

Pure colonies of Salmonella isolates were picked up from XLD plates with bacteriological loop, smeared onto separates clean glass slides with a drop of distilled water and fixed by gentle heating. Crystal violet was applied on each smear to stain for 1 minute and then washed with water. Then Lugol's iodine (as mordant) was applied for 1 minute and again washed with water. This was followed by the addition of $95 \%$ alcohol which serves as decolourizer and allowed to stand for a period of 10 seconds. After rinsing with water, safranin was added as a counter stain and then washed with water after 30 seconds. The preparation was air dried and examined under the microscope with high power objective (x100) using oil immersion (Mondal et al., 2008).

\subsection{Biochemical Characterization}

Isolated organisms with supporting growth characteristics of Salmonella were subjected to various biochemical tests. Biochemical tests such as Triple sugar iron (TSI), Simmons citrate and urease were used. The isolates of Salmonella were subcultured onto the biochemical media, incubated at $37^{\circ} \mathrm{C}$ for $24-48$ hours to check for phenotypic changes within the media (Global Salm-Surv, 2003). 
Prevalence and Antibiotic susceptibility pattern of Salmonella isolates from milk products and ..

\subsection{Antibiogram of Salmonella Isolates}

The sensitivity of the Salmonella isolates to ten different antimicrobial agents was performed through disc diffusion method to determine the drug sensitivity pattern. The antibiotics used were Ciprofloxacin $(10 \mu \mathrm{g})$, Streptomycin $(10 \mu \mathrm{g})$, Pefloxacin $(5 \mu \mathrm{g})$, Cotrimoxazole $(25 \mu \mathrm{g})$, Amoxycillin $(25 \mu \mathrm{g})$, Ofloxacin $(5 \mu \mathrm{g})$, Ceptriaxone $(30 \mu \mathrm{g})$, Gentamycin $(10 \mu \mathrm{g})$, Chloramphenicol $(30 \mu \mathrm{g})$ and Erythromycin $(5 \mu \mathrm{g})$ obtained from Fondiscs $^{\circledR}$. The Salmonella isolates were subcultured into Mueller-Hinton broth (Oxoid-CM0405) and then incubated at $37^{\circ} \mathrm{C}$ for 24 hours. Serial dilution was performed in the ratio of $2: 4$ of the broth and distilled water to reduce the degree of the turbidity of the broth culture. Then $1 \mathrm{ml}$ was dispensed onto Mueller-Hinton agar and the excess discarded. Antibiotic discs were applied aseptically to the surface of the plate with the help of sterile needle. This was incubated at $37^{\circ} \mathrm{C}$ for 24 hours under aerobic condition to observe for zones of inhibition, which were measured with the aid of a ruler (Mondal et al., 2008; Kaushik et al., 2014).

\subsection{Data Analyses}

Data were summarized into tables using descriptive statistics. Statistical Analysis System (SAS) version 9.3 was used to determine the Fisher's Exact Test for association between Salmonella and sources of samples. The $\mathrm{P}<0.05$ was considered significant.

\section{Results}

\subsection{Distribution of Salmonella in Milk Samples Collected from Retail Markets in Maiduguri Metropolis}

A total of one hundred samples of milk products; full cream milk (kindirmo) and skimmed milk (nono) collected from Bulumkutu and Maiduguri Monday market were analyzed. The number of samples from each location was 25, out of which the number of positive samples was found to be 10 . Higher prevalence of $24.00 \%$ was obtained for Salmonella from samples of skimmed milk (nono) in Maiduguri Monday market, followed by kindirmo that had $16.00 \%$ from the same location. No positive samples were obtained from Bulumkutu. The overall prevalence of Salmonella in milk samples was found to be $10.00 \%$ (Table 1).

The Salmonella isolates on XLD exhibited red colonies with black centres. The discrete colonies are indicated with arrows (Figure 1).

\subsection{Distribution of Salmonella in Samples Collected from Water Reservoirs on University Campus}

Fifty samples collected from six categorized sampling locations; namely hostels, faculties, departments, worship centres, lecture halls and others were analyzed to determine the prevalence of Salmonella. All the locations had one positive isolate for Salmonella (RA2, RB2, RBOT, RMG2, RMG3, REM, RFA, RFD, RFE, RFSC, RFV2, RHD, RMCM, RS1, RS2, RCG1, RCG2, RCM, RLG, RNF). The number of positive samples for Salmonella was 20 with the highest number (8) identified in reservoirs sampled from faculties, while the lowest value was zero from lecture hall reservoirs. The highest prevalence of $75.00 \%$ occurred in worship centres, followed by $61.45 \%$ for faculties, $50.00 \%$ for others and the lowest prevalence of $0.00 \%$ was obtained from reservoirs/dams in the premises of/or close to the lecture halls. The total prevalence of Salmonella from water sample was found to be $40.00 \%$ (Table 2).

\subsection{Antibiotic Sensitivity Test for Salmonella isolates}

The resistance and sensitivity pattern were displayed by fifteen Salmonella isolates to ten different antibiotic agents. Amoxicillin, Ceftriaxone and Erythromycin had the highest resistance, $15(100.00 \%)$ to Salmonella isolates, followed by Gentamycin, 12 (80.00\%), Cotrimoxazole, 8 (53.33\%), Chloramphenical, 7 (46.67) and Pefloxacin, 7 (46.67), Streptomycin, 4 (26.67) and Ofloxacin, 2 (13.33\%) and Ciprofloxacin, 2 $(13.33 \%)$. The highest intermediate value was $8(53.33 \%)$ for Streptomycin and Pefloxacin, while the lowest, 0 (0.00) were found in Amoxicillin, Ofloxacin, Ceftriaxone and Erythromycin. The Salmonella isolates were highly sensitive to Ofloxacin, 13 (86.67\%) and none to Amoxicillin, Ceftriaxone, Pefloxacin and Eryhromycin (Table 3).

\section{Discussion}

Pathogenic organism such as Salmonella has been a major concern to the public all over the world. The fact that milk contains a lot of nutrients made it havens for growth and development of Salmonella species (Ademola and Effiong, 2013). The microbial contamination of milk is multifactorial, originating from sources like feed, faeces, grasses and milking cow itself. Other possible causes include; unsterilized teats, utensils and unsafe water used in milk processing (Karshima et al., 2013). Several reports have documented the prevalence and distribution of Salmonella in milk, but there is paucity of information in the study area.

The prevalence of Salmonella observed in milk products was $10.00 \%$. This is in agreement with the findings of Rastegar et al. (2013) who reported a prevalence of $11 \%$ in Iran, but lower than the $20 \%$ reported by Tadesse and Dabassa (2012) in Ethiopia and higher than $8.7 \%$ reported by Karshima et al. (2013) in Kanam 
Prevalence and Antibiotic susceptibility pattern of Salmonella isolates from milk products and ..

local government area of Plateau State, Nigeria. These variations may be explained by the differences in management system of dairy farms, method of milking, hygienic practices and availability of potable water. This indicated that milk from Monday market can pose potential risk to public health when consumed or used in production of dairy products such as cheese, yoghurt and ice cream without being subjected to sufficient heat treatment. The negative result recorded by samples process from Bulumkutu may not be unconnected with the cleanliness of the source of water used for milk processing, proper pasteurization and maintenance of good hygiene.

Prevalence of $40.00 \%$ from water was recorded in this study which is higher than $16.12 \%$ reported by Carvalho et al. (2013) in Brazil. Consumption of such contaminated water without boiling can predispose individuals to Salmonella infection, more especially the immunocompromised or very young/old individuals. The presence of Salmonella in water reported in this study is not likely to originate from the water itself, but may possibly be associated with contamination from the user of those sources of water.

The antibiotic sensitivity test of fifteen Salmonella isolates to ten commonly used antibiotics revealed 100.00\% resistance to Amoxicillin, Ceftriaxone and Erythromycin, while Gentamicin had $80.00 \%$ and Cotrimoxazole was $53.33 \%$. This finding is in consonance with the $100.00 \%$ resistance to Erythromycin reported by Nesa et al. (2011), but higher than $75.00 \%$ to Amoxicillin. Additionally, Agada et al. (2014) reported lower resistance of $69.4 \%$ to Ceftriaxone than the one found in this study. However, the finding of the present study is in contrast with the report of Tesfaw et al. (2013) where $100.00 \%$ sensitivity to each of these antibiotics; Gentamycin, Ceftriaxone and Amoxicillin were reported. Moderate sensitivity of $53.33 \%$ to Streptomycin and Pefloxacin, $46.67 \%$ to Ciprofloxacin, and $86.67 \%$ sensitivity to Ofloxacin were found in this study. The $86.67 \%$ sensitivity to Ofloxacin concurs with 87\% reported by Falegan and Akere (2014). Antibiotic resistance is associated with sub therapeutic doses and frequent usage both in livestock and public health as they are relatively cheaper and commonly available. The effectiveness of Ofloxacin might be due to the difference in frequency of usage among the available antibiotics, nature of the drug and interaction with the bacteria as opined by Tesfaw et al. (2013).

\section{Conclusion}

This study has shown that the presence of Salmonella in milk may be attributed to unhygienic practices in milk processing, use of unsafe water, suboptimal pasteurization, inappropriate transportation and storage facilities and milking with bare hands. This poses a serious risk of Salmonella infection to consumers. Contaminated water for either drinking or food processing which may result from inappropriate treatment or recontamination is of public health concern. Therefore, consumption of such milk and water increases the risk of acquiring zoonotic diseases. The study revealed high sensitivity to Ofloxacin, moderate reaction to Pefloxacin and Streptomycin, but high resistance were observed to Amoxicillin, Ceftriaxone and Erythromycin.

Conflict of Interest The authors declare that there is no conflict of interest.

\section{Acknowledgements}

The authors are pleased to acknowledge the valuable contributions of Mr Ifraimu Naaya, Ahmed Kalif Bukar, Elijah Wafar and Mrs Briskila Ezra of the Veterinary Microbiology Laboratory, Department of Veterinary Microbiology and Parasitology, University of Maiduguri.

\section{References}

[1]. L.S. Ademola, and U.C. Effiong, Bacteriological quality and safety evaluation of raw cow milk in Ilorin, North-Central Nigeria. Nature and Sciences, 11(10), 2013, 73-79.

[2]. G.O.A. Agada, I. O. Abdullahi, M. Aminu, M. Odugbo, S. C. Chollom, P. R. Kumbish, and A.E.J. Okwori, Prevalence and antibiotic resistance profile of Salmonella isolates from commercial poultry and poultry farm-handlers in Jos, Plateau State, Nigeria. British Microbiology Research Journal, 4(4), 2014, 462-479.

[3]. Z. Bayu, B. Asrade, N. Kebede, Z. Sisay, and Y. Bayu, Identification and characterization of Salmonella species in whole egg purchased from local markets in Addis Ababa, Ethiopia. Journal of Veterinary Medicine and Animal Health, 5(5), 2013, 133-137

[4]. J.P.S. Cabral, Water microbiology. Bacterial pathogens and water. International Journal of Environmental Research and Public Health, 7, 2010, 3657-3703.

[5]. F.C.T. Carvalho, O. V. Sousa, E.M.R. Carvalho, E. Hofer, and R.H.S.F. Vieira, Antibiotic resistance of Salmonella species isolated from shrimp farming freshwater environment in Northeast Region of Brazil. Journal of Pathogens, 2013, 685193.

[6]. WHO Salmonella (non-typhoidal). Fact sheet $\mathrm{N}^{\mathrm{o}}$ 139. Food Safety Department, WHO/Geneva, 2013. http://www.who.int/mediacentre/factsheets/fs139/ Accessed on 19/09/2016.

[7]. Center for Food Safety and Public Health (CFSPH), Salmonellosis. Fast facts- Iowa State University, 2006, http://www.cfsph.iastate.edu/FastFacts/pdfs/nontyphoidal_salmonellosis

[8]. M. Demena, A. Workie, E. Tadesse, S. Mohammed, and T. Gebru, Water borne disease for the Ethiopian health centre team, 2003, pp. 1-92.

[9]. C.R. Falegan and G.A. Akere, Isolation of Salmonella spp in 'wara' (local cheese) from three different locations in Ado-Ekiti, Ekiti State, Nigeria. The Experiment, 23(4), 2014, 1628-1634. 
Prevalence and Antibiotic susceptibility pattern of Salmonella isolates from milk products and ..

[10]. Global Salm-Surv, A global Salmonella surveillance and laboratory support project of the World Health Organization In: Hendriksen, R. S. (DFVF) (edt). Laboratory Protocols Level 1 Training Course Identification of Salmonella 4th Ed, April 2003.

[11]. ISO, Microbiology-General guidance on methods for the detection of Salmonella. International Organization for Standardization, Geneve, Switzerland. $4^{\text {th }}$ Ed, 2002.

[12]. N.S. Karshima, V.A. Pam, Bata, S.I. P.A. Dung, and N.D. Panam, Isolation of Salmonella species from milk and locally processed milk products traded for human consumption and associated risk Factors in Kanam, Plateau State, Nigeria. Journal of Animal Production Advances, 3(3), 2013, 69-74.

[13]. P.A. Kaushik, S. Kumari, S. Bharti, and K. Dayal, Isolation and prevalence of Salmonella from chicken meat and cattle milk collected from local markets of Patna, India. Veterinary World, 7(2), 2014, 62-65.

[14]. J. Kemal, A Review on the public health importance of bovine salmonellosis. Journal of Veterinary Science Technology, 5, 2014, 175. doi:10.4172/2157-7579.1000175

[15]. T. Mondal, Khan, M.S.R. Alam, M. Purakayastha, M. Das, M. and Saddique, M.P. Isolation, identification and characterization of Salmonella from duck. Bangladesh Journal of Veterinary Medicine, 6(1), 2008, 7-12.

[16]. B.N. Nagpal, S. Singh, S.K. Chand, A. Singh, A. Srivastava, and V.K. Dua, Microbiological quality of drinking water in the villages, rehabilitation and resettlement colonies located in the area of major dams of Narmada Basin, India. Webmed Central Microbiology, 2(8), 2011, WMC002084.

[17]. M.K. Nesa, M.S.R. Khan, and M. Alam, Isolation, Identification and characterization of Salmonella serovars from diarrhoeic stool samples of humans. Bangladash Journal of Veterinary Medicine, 9(1), 2011, 642-643.

[18]. C.F. Pui, W.C. Wong, L.C. Chai, R. Tenung, P. Jeyaletchumi, M.S. Noor Hidayah, A. Ubong, M.G. Farinazleen, Y.K. Cheah, and R. Son, Salmonella: foodborne pathogen. International Food Research Journal, 18, 2011, 465-473.

[19]. H. Rastegar, H. Ahmadi, A. Kaveh, A. Mina, A. Shima, H. Nehshabouri, M. Akbari, H. Rassam, S. Parvizi, and S. Anjarani, Detection, isolation and assessment of Salmonella enteritidis in milk by conventional culture methods and real-time PCR in Iran. American Journal of Research Communication, 1(8), 2013, 81-97.

[20]. C. Ricci-Tam, Salmonella-Description, pathogenesis, and symptoms. Cluster 7 July 28, 2008.

[21]. T. Tadesse, and A. Dabassa, Prevalence and antimicrobial resistance of Salmonella isolated from raw milk samples collected from Kersa District, Jimma zone, South-West Ethiopia. Journal of Medical Sciences, 12(7), 2002, 224-228.

[22]. L. Tesfaw, B. Taye, S. Alemu, H. Alemayehu, Z. Sisay, and H. Negussle, Prevalence and antimicrobial resistance profile of Salmonella isolates from dairy products in Addis Ababa, Ethiopia. Academic Journals, 7(43), 2013, 5046-5050.

[23]. H.C. Wegener, T. Hald, D.L.F. Wong, M. Madsen, H. Korsgaard, F. Bager, F. Gerner-Smidt, and K. Mølbak, Salmonella Control Programs in Denmark. Emerging Infectious Diseases, 9(7), 2003, 774-780.

[24]. D.G. White, S. Zhao, R. Sudler, S. Ayers, S. Friedman, S. Chen, P.F. Mcdermott, S. Mcdermott, D.D. Wagner, and J. Meng, The isolation of antibiotic-Resistant Salmonella from retail ground meats. The New England Journal of Medicine, 345(16), 2001, 11471154.

[25]. S. Zaki, D. Abd-El-Haleem, E. El-Helow, and M. Mustafa, Molecular and biochemical diagnosis of Salmonella in wastewater. Journal of Applied Science and Environmental Management, 13, 2009, 83e92.

Table 1: Distribution of Salmonella in Milk Samples collected from Retail Markets in Maiduguri Metropolis

\begin{tabular}{|c|c|c|c|c|c|}
\hline $\begin{array}{c}\text { Sampling } \\
\text { Location }\end{array}$ & $\begin{array}{c}\text { Sample } \\
\text { Identity }\end{array}$ & Milk Type & $\begin{array}{c}\text { Total no. } \\
\text { Collected }\end{array}$ & $\begin{array}{c}\text { Number } \\
\text { Positive }\end{array}$ & $\begin{array}{c}\text { Prevalence } \\
\text { (\%) }\end{array}$ \\
\hline Bulumkutu & BK & $\begin{array}{c}\text { Full cream } \\
\text { milk(kindirmo) }\end{array}$ & 25 & 0 & 0.00 \\
\hline Bulumkutu & BN & Skimmed milk (nono) & 25 & 0 & 0.00 \\
\hline $\begin{array}{c}\text { Maiduguri } \\
\text { Monday Market }\end{array}$ & MMK & $\begin{array}{c}\text { Full cream } \\
\text { milk(kindirmo) }\end{array}$ & 25 & 4 & 16.00 \\
\hline $\begin{array}{c}\text { Maiduguri } \\
\text { Monday Market }\end{array}$ & MMN & Skimmed milk (nono) & 25 & 6 & 24.00 \\
\hline Total & & & 100 & 10 & 10.00 \\
\hline
\end{tabular}

Fisher's Exact Test: $\mathrm{P}<0.5000$ was not statistically significant

Table 2: Distribution of Salmonella in Samples Collected from Water Reservoirs on University Campus

\begin{tabular}{|c|c|c|c|c|}
\hline Location & $\begin{array}{c}\text { Total no. } \\
\text { Collected }\end{array}$ & $\begin{array}{c}\text { Positive Salmonella with Respect to } \\
\text { Specific Location }\end{array}$ & $\begin{array}{c}\text { Number } \\
\text { Positive }\end{array}$ & $\begin{array}{c}\text { Prevalence } \\
(\%)\end{array}$ \\
\hline Hostels & 18 & RA2, RB2, RBOT, RMG2, RMG3 & 5 & 27.78 \\
\hline Faculties & 13 & $\begin{array}{c}\text { REM, RFA, RFD, RFE, RFSC, } \\
\text { RFV2, RHD, RMCM, }\end{array}$ & 8 & 61.54 \\
\hline Departments & 9 & RS1, RS2 & 2 & 22.22 \\
\hline Worship Centres & 4 & RCG1, RCG2, RCM & 3 & 75.00 \\
\hline Lecture halls & 2 & Nil & Nil & Nil \\
\hline Others & 4 & RLG, RNF & 2 & 50.00 \\
\hline Total & 50 & & 20 & 40.00 \\
\hline
\end{tabular}

Fisher Exact Test: $\mathrm{P}<0.0167$ was statistically significant. 
Table 3: Antibiotic Sensitivity Test for Salmonella isolates

\begin{tabular}{|l|c|l|c|}
\hline $\begin{array}{l}\text { Antibiotic } \\
\text { Agents }\end{array}$ & $\begin{array}{c}\text { Resistance } \\
(\mathbf{\%})\end{array}$ & $\begin{array}{c}\text { Intermediate } \\
(\mathbf{\%})\end{array}$ & $\begin{array}{c}\text { Sensitive } \\
(\mathbf{\%})\end{array}$ \\
\hline Amoxicillin & $15(100.00)$ & $0(0.00)$ & $0(0.00)$ \\
\hline Ofloxacin & $2(13.33)$ & $0(0.00)$ & $13(86.67)$ \\
\hline Streptomycin & $4(26.67)$ & $8(53.33)$ & $3(20.00)$ \\
\hline Chloramphenicol & $7(46.67)$ & $3(20.00)$ & $5(33.33)$ \\
\hline Ceftriaxone & $15(100.00)$ & $0(0.00)$ & $0(0.00)$ \\
\hline Gentamicin & $12(80.00)$ & $1(6.67)$ & $2(13.33)$ \\
\hline Pefloxacin & $7(46.67)$ & $8(53.33)$ & $0(0.00)$ \\
\hline Cotrimoxazole & $8(53.33)$ & $5(33.33)$ & $2(13.33)$ \\
\hline Ciprofloxacin & $2(13.33)$ & $7(46.67)$ & $6(40.00)$ \\
\hline Erythromycin & $15(100.00)$ & $0(0.00)$ & $0(0.00)$ \\
\hline
\end{tabular}

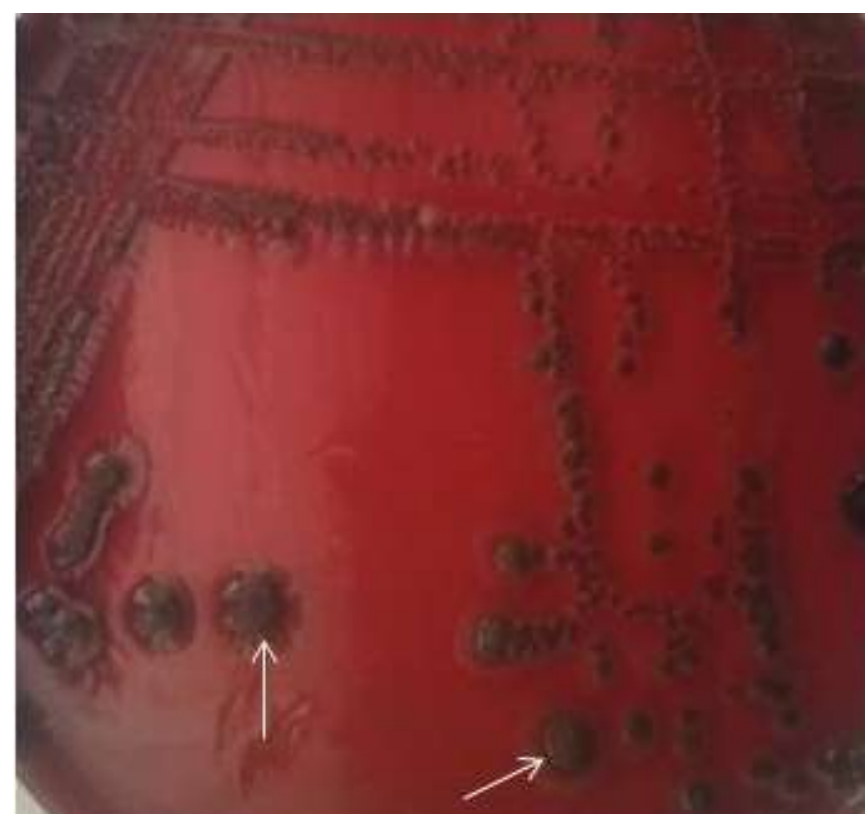

Figure 1: Salmonella isolates on XLD appearing as Pink-red colonies with black centres 